\title{
Selecting Iodine-Enriched Vegetables and the Residual Effect of Iodate Application to Soil
}

\author{
JiU-Lan Dai, ${ }^{1,2}$ Yong-Guan ZhU, ${ }^{*},{ }^{1}$ Min Zhang, ${ }^{2}$ \\ AND YI-ZHONG HUANG ${ }^{1}$ \\ ${ }^{1}$ Research Center for Eco-environmental Sciences, \\ Chinese Academy of Sciences, Beijing 100085, China; and \\ ${ }^{2}$ College of Environment and Resource, Shandong \\ Agricultural University, Tai'an 271018, China
}

Received November 20, 2003; Accepted January 15, 2004

\begin{abstract}
A greenhouse pot experiment was conducted to select vegetables for iodine uptake. The residual effect of iodate fertilization on the growth of and iodine uptake by spinach plants were also investigated. Six vegetables, including leafy vegetables (pakchoi [Brassica chinensis L.], spinach [Spinacia oleracea L.]), tuber vegetables (onion [Allium cepa L.]), shoot vegetables (water spinach [Ipomoea aquatica Forsk.], celery [Apium graveolens L.]), and root vegetables (carrot [Daucus carota var. sativa DC.]) were examined. Results showed that the concentrations of iodate in soil had significant effect on the biomass of edible parts of pakchoi and spinach $(p<0.01)$, whereas the concentrations of iodate in soil had no significant effect on that of carrots, water spinach, celery, and onion. Iodine concentrations in edible parts of vegetables and the transfer factors $\left(\mathrm{TF}_{\text {edible parts }}\right)$ of soil-to-edible parts of vegetables significantly increased with increasing iodine concentrations in soil $(p<0.001)$, and iodine concentrations in edible parts and $\mathrm{TF}_{\text {edible parts }}$ of spinach were much higher than those of other vegetables at any treatment. Both transfer coefficients for edible parts $\left(\mathrm{TC}_{\text {edible parts }}\right)$ and for aerial parts $\left(\mathrm{TC}_{\text {aerial parts }}\right)$ of vegetables changed differently with increasing iodine concentrations in the soil, and $\mathrm{TC}_{\text {edible parts }}$ and $\mathrm{TC}_{\text {aerial parts }}$ of spinach were higher than those of other vegetables. Therefore, spinach (leafy vegetable) was considered as an efficient vegetable for iodine biofortification. Further experiment showed that there is considerable residual effect of soil fertilization with iodate.
\end{abstract}

Index Entries: Biofortification; iodine; iodate; vegetables; spinach.

* Author to whom all correspondence and reprint requests should be addressed. 


\section{INTRODUCTION}

Iodine is an essential element for animal and human health and is one of the first recognized associations between trace elements in the environment and human health. Iodine deficiency disorders (IDDs) are a group of diseases that result from a relative lack of iodine in the diet. IDDs include goiter (a swelling of the thyroid gland in the neck), cretinism, reduced IQ, miscarriages, birth defects, and deaths around the time of birth. The main cause of IDDs is the general lack of iodine in the local environments or food chains.

Iodine deficiency was once considered a minor problem, causing goiter-an unsightly but seemingly benign cosmetic blemish. However, it is now known that the effects on the developing brain are much more deadly and constitute a threat to the social and economic development of many countries, and it causes low productivity (ICCIDDs).

Some investigations have indicated that the daily iodine intake mainly comes from grain and vegetables, accounting for $52-70 \%$ of the total iodine intakes in China (1) and $92.4 \%$ for those living in developed countries (data from the UK National Diet and Nutrition Survey 1997-1998). Therefore, it is generally accepted that food is the main source of daily iodine intake. In view of the major source of iodine intake, many remediation programs, such as iodized salt and iodized oil, have been practiced worldwide. However, the effectiveness of these measures depends largely on the social economic and cultural situation of a population group of concern. In Xinjiang Province of China, for example, local people prefer rock salt (freely available), which is very low in iodine, and even if iodine is supplemented in salt, iodine loss during Chinese cooking could be substantial (2). Therefore, alternative iodine supplementation is needed to complement the traditional approaches.

Supplementation of trace elements in the food chain through plant uptake is generally termed biofortification and is believed to be a cost-effective way to improve human nutrition (3). Iodine supplementation in the food chain has been attempted recently in Xinjiang-for example, by the irrigation of paddy soil with iodized water to reduce iodine deficiency (4). This practice has been extended to several prefectures in Xinjiang and has proved to be a useful approach in reducing iodine-deficiency-related health problems locally (5). However, it has been demonstrated that iodine cannot be easily accumulated in the grains of cereal crops $(6,7)$, such as rice and wheat. Vegetables must be considered to have an advantage in concentrating iodine because iodine accumulation in the edible parts of vegetables is largely dependent on xylem transport (6). Our previous results (2) showed that the solution-to-leaf transfer factors were higher than those reported for rice in solution culture (7), and much higher than those reported for wheat grains (average $=0.0016$ ) grown in field soils (8). Iodine concentration in spinach leaves was enough to supplement iodine through 
Table 1

General Properties of Soils Used in This Study

\begin{tabular}{|c|c|c|c|c|c|c|c|c|c|}
\hline $\begin{array}{l}\text { Soil type } \\
\text { (12) }\end{array}$ & $\begin{array}{c}\mathrm{pH} \\
\left(\mathrm{H}_{2} \mathrm{O}\right)\end{array}$ & $\begin{array}{l}\mathrm{OM} \\
(\mathrm{g} \\
\left.\mathrm{kg}^{-1}\right)\end{array}$ & $\begin{array}{c}\text { CEC(c } \\
\mathrm{mol} / \mathrm{kg} \\
\text { soil) }\end{array}$ & $\begin{array}{c}\text { Free } \\
\mathrm{Fe}_{2} \mathrm{O}_{3} \\
(\mathrm{~g} \\
\left.\mathrm{kg}^{-1}\right)\end{array}$ & $\begin{array}{c}\text { Free } \\
\mathrm{Al}_{2} \mathrm{O}_{3} \\
(\mathrm{~g} \\
\left.\mathrm{kg}^{-1}\right)\end{array}$ & $\begin{array}{l}\text { Available } \\
\mathrm{N} \\
\left(\mathrm{mg} \mathrm{kg}^{-1}\right)\end{array}$ & $\begin{array}{c}\text { Available } \\
\mathrm{P} \\
\left(\mathrm{mg} \mathrm{kg}^{-1}\right)\end{array}$ & $\begin{array}{c}\text { Available } \\
\mathrm{K} \\
\left(\mathrm{mg} \mathrm{kg}^{-1}\right)\end{array}$ & $\begin{array}{c}\text { Total I } \\
\left(\mathrm{mg} \mathrm{kg}^{-1}\right)\end{array}$ \\
\hline $\begin{array}{c}\text { Udic } \\
\text { Luvisols }\end{array}$ & 7.85 & 13.9 & 9.16 & 10.8 & 1.07 & 65.39 & 14.78 & 59.67 & 0.88 \\
\hline
\end{tabular}

dietary intake with an iodate concentration of $1 \mu M$ (about $0.1 \mathrm{mg} / \mathrm{kg}$ ) in the growth medium.

The present experiment therefore aimed (1) to screen various vegetable plants for efficient iodine accumulation, (2) to investigate the portioning of iodine in different tissues of various vegetable crops, and (3) to examine the residual effect of iodine-containing soil application fertilizers.

\section{MATERIALS AND METHODS}

\section{Soil}

Soil was obtained from the Huairou district of Beijing, China. The general properties of the soil used in this study are shown in Table 1. The soil sample was air-dried and ground to pass a 2-mm sieve for planting vegetables and were then sieved through a 1-mm sieve for soil $\mathrm{pH}$, analysis, ground to pass through a $0.25-\mathrm{mm}$ sieve for total iodine, cation-exchange capacity (CEC), and free $\mathrm{Fe} / \mathrm{Al}$ oxides analysis, and through a $0.125-\mathrm{mm}$ sieve for organic matter determination.

\section{Vegetables}

The vegetables used in this experiment were as follows: pakchoi (Brassica chinensis L.), spinach (Spinacia oleracea L.), carrots (Daucus carota var. sativa DC.), water spinach (Ipomoea aquatica Forsk.), celery (Apium graveolens L.), and onion (Allium cepa L.).

\section{Fertilizers}

Potassium iodate $\left(\mathrm{KIO}_{3}\right)$ was used as the iodine fertilizer. Basal fertilizers were $\mathrm{NH}_{4} \mathrm{NO}_{3}\left(150-\mathrm{mg} \mathrm{N} / \mathrm{kg}\right.$ soil) and $\mathrm{KH}_{2} \mathrm{PO}_{4}(150-\mathrm{mg} \mathrm{P} / \mathrm{kg}$ soil and 189-mg K/ kg soil). 


\section{Determination of Soil Properties}

Soil $\mathrm{pH}$ was determined with a Thermo Orion (Model 828) in a $1: 2.5$ suspension in $\mathrm{H}_{2} \mathrm{O}$. Organic matter was determined by oxidation with of potassium dichromate titration of $\mathrm{FeSO}_{4}$. Free-Fe/ $\mathrm{Al}$ oxides were extracted with DCB reagent (dithionite citrate sodium-bicarbonate reagent); Fe was determined by atomic absorption spectrometry (AAS) (Z-6100, Hitach Co., Japan) and Al was determined by ICP-AES (Optima 2000, PE Co., USA). Cation exchange capacity (CEC) was determined with the method of acetic ammonium saturation. Procedures for the determination of soil properties were standard methods recommended by the Chinese Society of Soil Science (9). Total iodine in soil was determined by neutron activation analysis (NAA) (1).

\section{Plant Culture}

The soil pot experiment was carried out in a greenhouse with temperature of $25 \pm 3^{\circ} \mathrm{C}$ during the day and $20 \pm 3^{\circ} \mathrm{C}$ at night. Seeds of vegetables were disinfected in $10 \% \mathrm{H}_{2} \mathrm{O}_{2}$ solution for 10 min followed by thorough washing in deionized water. Seeds were then germinated on moist filter paper for 2-3 d. Four germinated seeds were sown in pots with $1.2 \mathrm{~kg}$ soil per pot. The soil was supplied with the following amounts of iodine as $\mathrm{KIO}_{3}$ in solution: $0,1.0$, and $5.0 \mathrm{mg} \mathrm{I} / \mathrm{kg}$ soil and were designated as treatment 1 , treatment 2 , and treatment 3 , respectively. Basal fertilizers were applied in the same time as iodine was applied by thorough mixing. Ten days after emergence, seedlings were thinned to two uniform plants for pakchoi, spinach, and water spinach, and one for carrots, celery, and onion per pot. There were four replicates for each treatment. The water content of the soil was adjusted to $20 \%$. Throughout the growth period, water losses were compensated by the addition of deionized water by weighing. The second plantation of spinach plants were sown in homogenized soil about 3 mo after harvesting the first plantation of spinach.

Because of the different growth patterns of different plant species, plants were harvested at different times. Pakchoi and spinach was 7 wk after seedling, carrots and water spinach was $13 \mathrm{wk}$, and onion and celery was 19 wk. After harvest, plants were divided into roots and leaves for pakchoi and spinach, roots and shoots for carrots, water spinach, and celery, and roots, leaves, and stems for onion, and then washed with deionized water and dried with soft paper; fresh weights were determined immediately. Plant tissues were then oven-dried at $70^{\circ} \mathrm{C}$ for $72 \mathrm{~h}$, and dry weights were determined for all tissues. Tissues were all ground for iodine analysis by NAA (1).

\section{Iodine Analysis}

Neutron activation analysis was used to analyze iodine in plant tissues $(2,8,13)$ and the procedure is described briefly as follows: Dried plant 
samples and reference materials (150-200 mg per sample) were doublesealed in a polyethylene tube for irradiation. Each sample was irradiated for 15-20 $\mathrm{min}$ in a miniature neutron source reactor (MNSR) of the Chinese Institute of Atomic Energy Science in Beijing. The thermal neutron flux used was $7.0 \times 10^{11} \mathrm{n} / \mathrm{cm}^{2} / \mathrm{s}$. In the irradiation facility, samples were shielded in a $\mathrm{BN}$ (boron nitride) box.

The radioactivity of ${ }^{128} \mathrm{I}$ was measured by high-purity Ge detectors (Ortec, USA) for $10 \mathrm{~min}$ at $442.09 \mathrm{keV}$. Analysis accuracy was measured on the reference material and was between $2 \%$ and $3.6 \%$.

\section{Data Analysis}

Iodine concentrations (IC) in leaves, shoots, stems, and roots were calculated on a fresh-weight basis. The soil-to-edible parts transfer factors $\left(\mathrm{TF}_{\text {edible parts }}\right)$ were calculated as follows:

$$
\mathrm{TF}_{\text {edible parts }}=\left[\mathrm{IC}_{\text {edible parts }}\right]^{\mathrm{fresh}} / \mathrm{IC}_{\text {soil }}
$$

where $\left[\mathrm{IC}_{\text {edible parts }}\right]^{\text {fresh }}$ is the iodine concentration in edible parts on a freshweight basis and $\mathrm{IC}_{\text {soil }}$ is the iodine concentration in the corresponding soil. The iodine translocation coefficients $\left(\mathrm{TC}_{\text {edible parts or aerial parts }}\right)$ were defined as the percentage total iodine uptake in edible parts (or aerial parts).

All data are subjected to the analysis of variation (ANOVA, two way) performed using the Windows-based Genstat (6th edition; NAG, England).

\section{RESULTS}

\section{Biomass Production}

The biomass of edible parts of the vegetables on a fresh-weight basis grown with different iodate levels are shown in Table 2. Because vegetables were harvested at different times, statistical analysis was not performed for interspecific differences; this is also true for other parameters. The concentrations of iodate in soil had a significant effect on the biomass of edible parts of pakchoi and spinach $(p<0.01)$; application of iodine at a concentration of $5 \mathrm{mg} \mathrm{I} / \mathrm{kg}$ soil significantly reduced the edible part biomass, whereas the concentrations of iodate in soil had no significant effect on the edible parts biomass of carrots, water spinach, celery, and onions, although there were some fluctuations at different levels of iodate.

\section{Iodine Concentrations in Edible Parts of Vegetables}

Increasing iodine applications to the soil generally enhanced iodine accumulation in the edible parts of all vegetables ( $p<0.001$; see Fig. 1$)$. Under the control (Treatment 1), iodine concentration in the edible part of pakchoi was below the detection limit. In all treatments, spinach always had the highest iodine concentrations in the edible part. Although no attempt was 
Table 2

Biomass of Edible Parts of Vegetables Based on Fresh Weights (g)

\begin{tabular}{ccccccc}
\hline \multirow{2}{*}{ Edible parts } & Pakchoi & Spinach & Carrot & Waterspinch & Celery & Onion \\
\cline { 2 - 7 } & leaf & leaf & root & shoot & shoot & tuber \\
\hline Treatment 1 & $61.21 \pm 1.65 \dagger$ & $17.23 \pm 1.39$ & $15.62 \pm 1.98$ & $11.38 \pm 0.59$ & $25.04 \pm 4.80$ & $12.44 \pm 1.12$ \\
Treatment 2 & $62.72 \pm 2.19$ & $17.40 \pm 0.89$ & $14.33 \pm 1.67$ & $12.31 \pm 0.88$ & $14.36 \pm 3.70$ & $17.33 \pm 0.64$ \\
Treatment 3 & $51.13 \pm 2.09$ & $10.39 \pm 1.07$ & $16.28 \pm 2.60$ & $11.91 \pm 0.40$ & $15.50 \pm 0.01$ & $13.42 \pm 2.08$ \\
\hline & $P=0.005 \ddagger$ & $P=0.005$ & NS§ & NS & NS & NS \\
LSD $_{0.05}$ & 6.37 & 3.73 & 6.77 & 2.09 & 14.72 & 4.80 \\
\hline
\end{tabular}

† The means \pm standard error $(n=4)$.

$\ddagger$ Significant at $p=0.005$.

$\S$ NS: not significant.

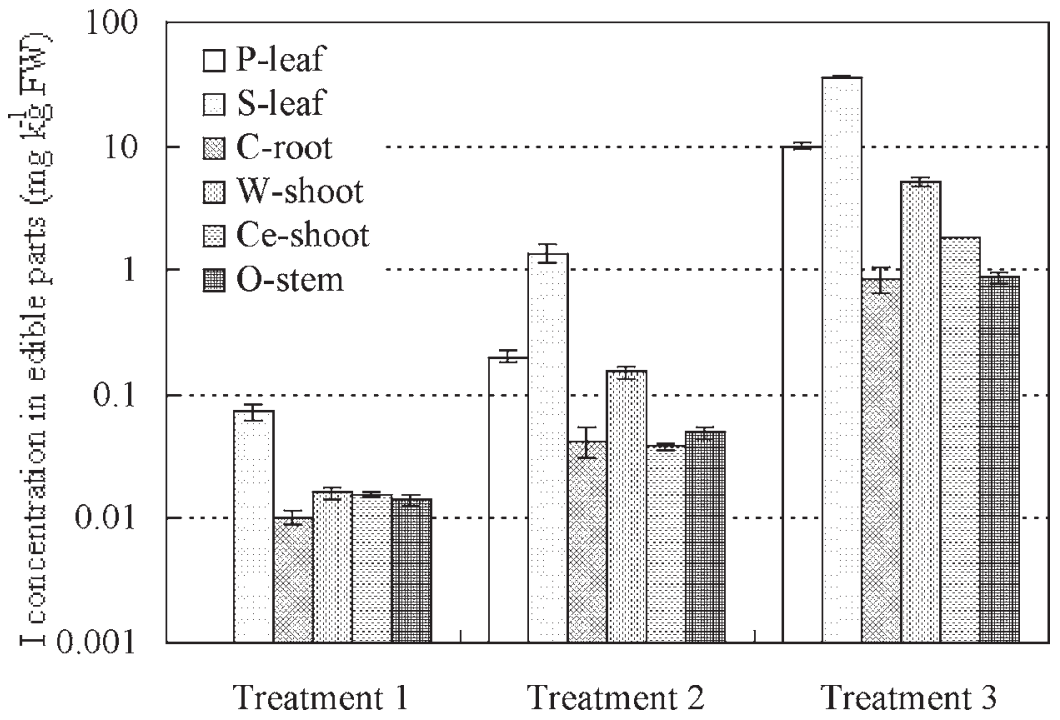

Fig. 1. Iodine concentration in edible parts of the vegetables on a freshweight basis (P: pakchoi, S: spinach, C: carrot, W: water spinach, Ce: celery, O: onion). Bars: standard errors $(p<0.001, n=4)$.

made to compare the difference statistically in iodine concentrations between plant species, iodine concentrations in edible parts of spinach, pakchoi, and water spinach were generally higher than other plant species.

\section{Distribution of Iodine in Vegetables}

As far as biofortification of iodine is concerned, iodine accumulation in plant edible parts is of practical importance. Iodine translocation coefficients 


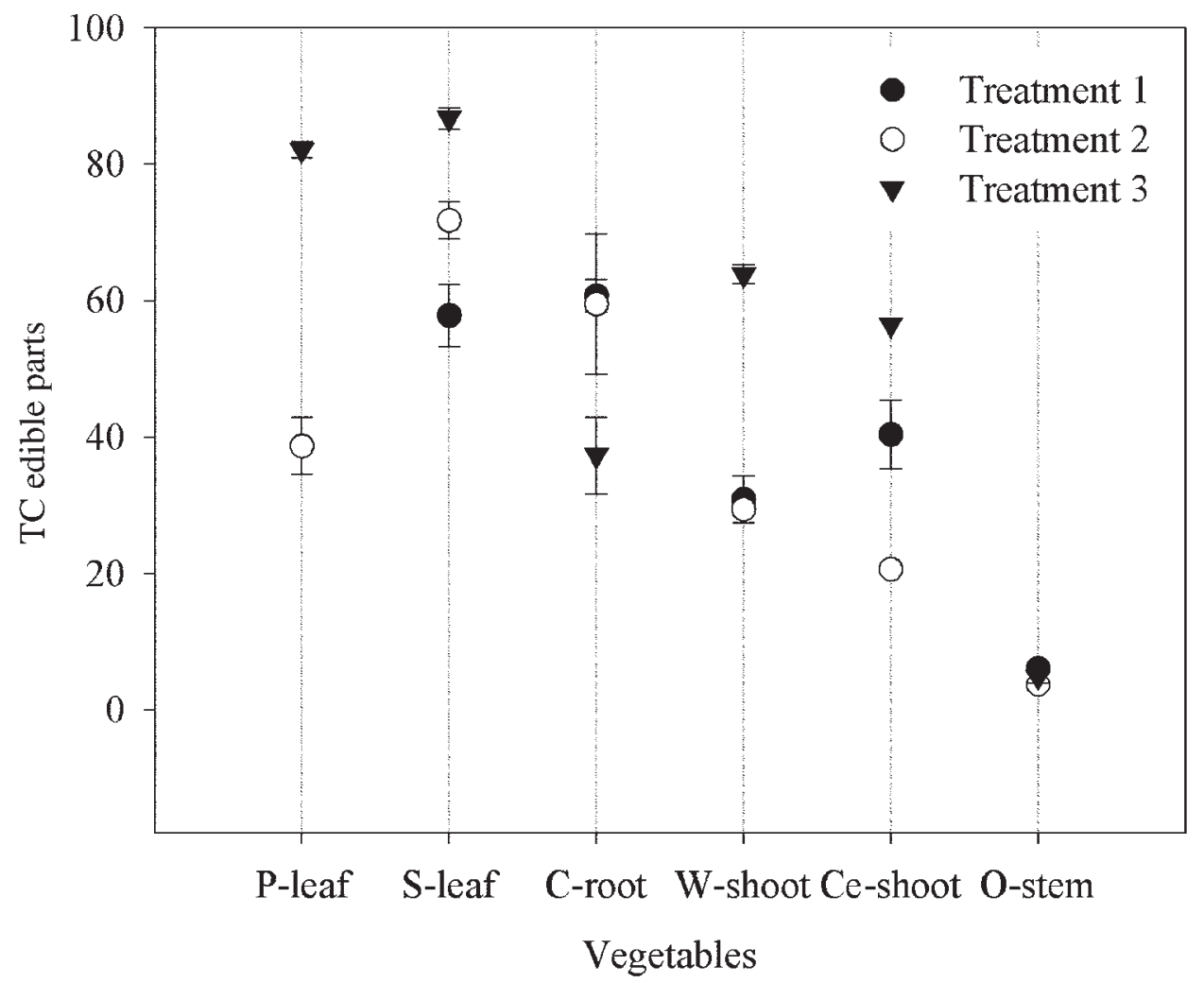

Fig. 2. Iodine distribution coefficients in edible parts of vegetables treated with different iodine treatments (P: pakchoi, S: spinach, C: carrot, W: water spinach, Ce: celery, O: onion). Bars: standard errors $(n=4)$.

in edible parts $\left(\mathrm{TC}_{\text {edible parts }}\right)$ of vegetables are therefore used to describe iodine accumulation in edible parts; the $\mathrm{TC}_{\text {edible parts }}$ for different plants are shown in Fig. 2. The $\mathrm{TC}_{\text {edible parts }}$ of different vegetables changed differently in response to increasing iodine application to the soil. The $\mathrm{TC}_{\text {edible parts }}$ for spinach was much higher than that of other vegetables in all treatments, except that the $\mathrm{TC}_{\text {edible parts }}$ of carrots was slightly higher than that of spinach in Treatment 1.

The iodine translocation coefficients to aerial parts $\left(\mathrm{TC}_{\text {aerial parts }}\right)$ of vegetables were all higher in Treatment 3 than in other treatments, with spinach being the highest (see Fig. 3). The $\mathrm{TC}_{\text {aerial parts }}$ were similar or higher in Treatment 2 than in Treatment 1, with the exception of celery. The transfer factors for soil-to-edible parts of vegetables $\left(\mathrm{TF}_{\text {edible parts }}\right)$ are shown in Fig. 4. The data indicated that the $\mathrm{TF}_{\text {edible parts }}$ of vegetables increased significantly with increasing iodine concentrations in the soil $(p<0.001)$. The $\mathrm{TF}_{\text {edible parts }}$ of spinach was much higher than that of other vegetables in all 


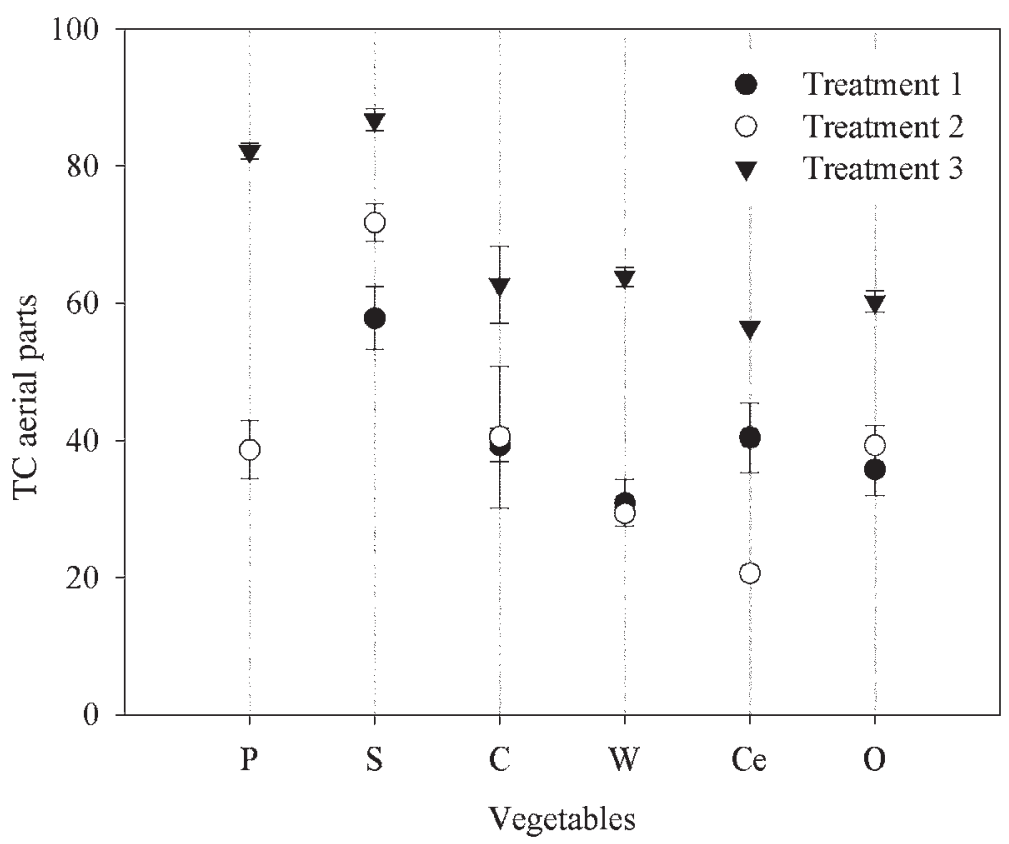

Fig. 3. Percent of iodine content in aerial parts of vegetables treated with different iodine treatments (P: pakchoi, S: spinach, C: carrot, W: water spinach, Ce: celery, O: onion). Bars: standard errors $(n=4)$.

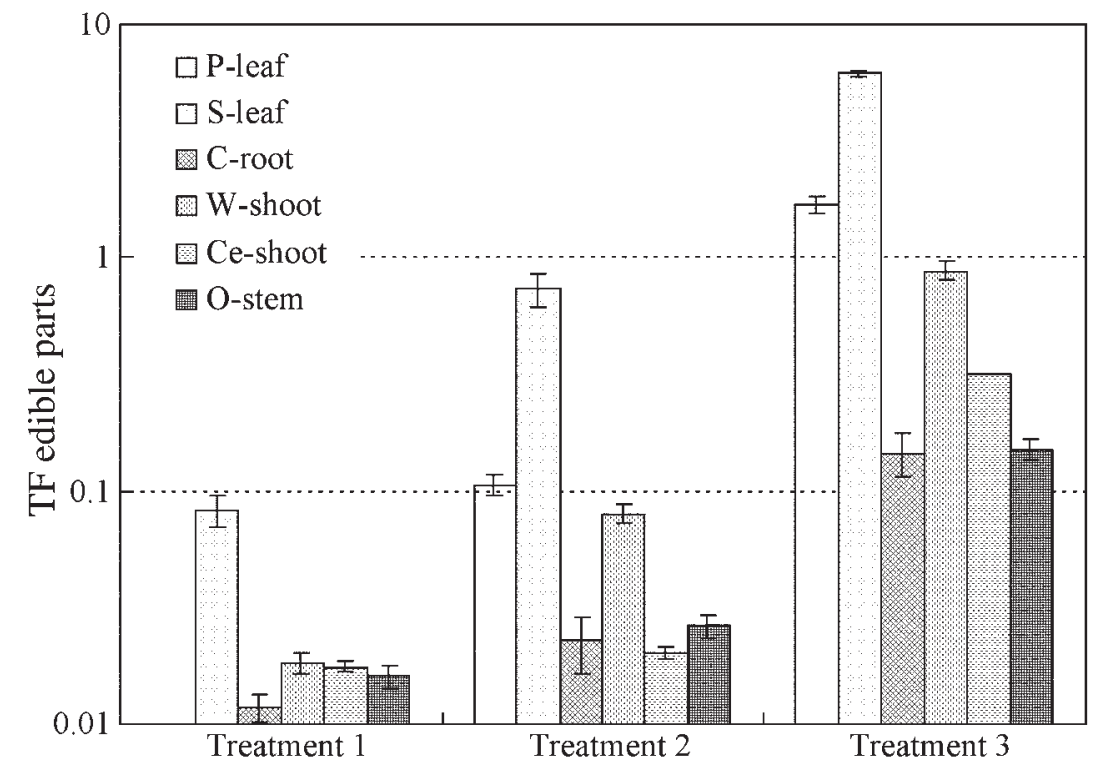

Fig. 4. Soil to edible parts transfer factors for vegetables treated with different iodine treatments (P: pakchoi, S: spinach, C: carrot, W: water spinach, Ce: celery, O: onion). Bars: standard errors $(p<0.001, n=4)$. 
Table 3

Biomass of Spinach on a Fresh-weight Basis of First and Second Planting

\begin{tabular}{cccc}
\hline & Treatments & Roots $(\mathrm{g})$ & Leaves $(\mathrm{g})$ \\
\hline \multirow{2}{*}{ First } & 1 & $2.23 \pm 0.33 \uparrow$ & $17.23 \pm 1.39$ \\
plantation & 2 & $2.31 \pm 0.39$ & $17.40 \pm 0.89$ \\
& 3 & $1.09 \pm 0.18$ & $10.39 \pm 1.07$ \\
\hline \multirow{2}{*}{ LSD $_{0.05}$} & & $\mathrm{P}<0.05 \ddagger$ & $P=0.005$ \\
\hline \multirow{2}{*}{ Second } & 1 & 0.983 & 3.731 \\
plantation & 2 & $3.80 \pm 0.34$ & $15.57 \pm 0.57$ \\
& 3 & $4.50 \pm 0.093$ & $17.71 \pm 1.61$ \\
\hline & $4.65 \pm 0.74$ & $19.24 \pm 1.22$ \\
LSD $_{0.05}$ & & $\mathrm{NS} \S$ & $\mathrm{NS}$ \\
\hline
\end{tabular}

† The means \pm standard error $(n=4)$.

$\ddagger$ Significant at $p<0.05$.

$\S$ NS: not significant.

treatments, about 4.6-6.9 times that of other vegetables in Treatment 1, 6.9-36.3 times in Treatment 2, and 3.6-40.7 times in Treatment 3.

\section{Effects of the Residual Iodate in Soil on the Growth and Iodine Accumulation by Spinach Plants}

The biomass of spinach on a fresh-weight basis at first and second planting are shown in Table 3. The biomass of both leaves and roots of spinach at first planting increased slightly when the iodine concentration in soil increased from 0 to $1 \mathrm{mg} \mathrm{I} / \mathrm{kg}$ soil and then decreased significantly when the iodine concentration in soil increased from 1 to $5 \mathrm{mg}$ $\mathrm{I} / \mathrm{kg}$ ( $p<0.01$ for leaves and $p<0.05$ for roots), whereas those at the second planting increased gradually with increasing iodine concentrations in soil.

Iodine concentrations in both roots and leaves of spinach on a freshweight basis at first and second planting increased with increasing iodine concentrations in the soil $(p<0.001$; see Fig. 5); however, there was no significant difference in biomass between Treatment 1 and Treatment 2 except for that of leaves at the second planting. Iodine concentrations in both roots and leaves of spinach at the first planting were much higher than those at the second planting. 


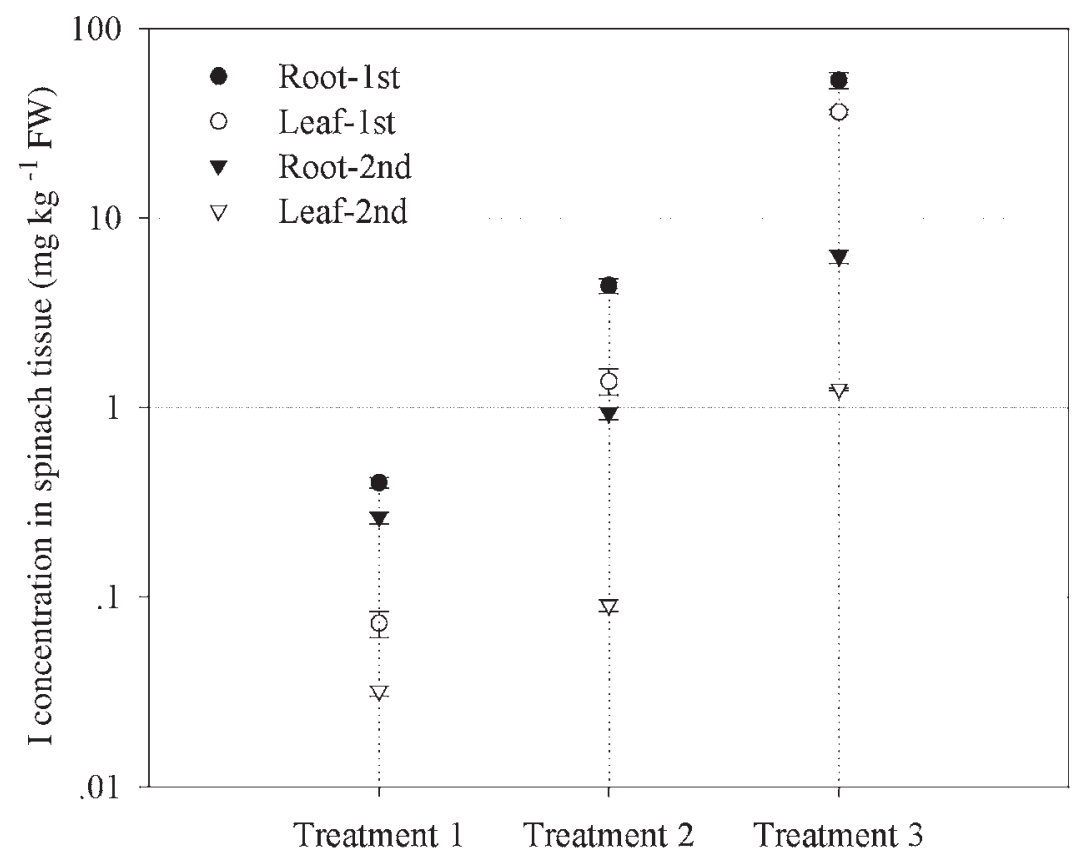

Fig. 5. Iodine concentration in spinach tissues on a fresh-weight basis of first and second planting $(p<0.001, n=4)$.

\section{DISCUSSION}

Although there is no direct evidence on the essentiality of iodine to plant growth, low iodine concentrations in the growth environment is beneficial to a number of plant species (10) and high concentrations of iodine were detrimental to plant growth $(2,7)$. In the present study, it was observed that different plant species responded differently to increasing iodine in soil. Nevertheless, no beneficial effect of iodine supplementation on plant growth was observed, and for some vegetable crops, iodine application up to $5 \mathrm{mg} \mathrm{I} / \mathrm{kg}$ reduced the yields of a number of crops. It should be noted that if soil application of iodine is used to biofortify vegetable crops, one should avoid the excessive application of iodine to soils in order to maintain reasonable crop yields.

Iodine accumulation in the edible parts of vegetables is largely dependent on xylem transportation (6); iodine accumulation ability varies between different vegetables. The iodine accumulation ability of vegetables in the present study was as follows: spinach > pakchoi $>$ water spinach > other vegetables; therefore, spinach can be considered as a relatively efficient vegetable targeted for iodine biofortification. According to our previous study (2), when grown at iodine concentration of around 0.1 $\mathrm{mg} / \mathrm{L}$ in the growth medium, iodine concentration in spinach leaves 
reached $3 \mathrm{mg} / \mathrm{kg}$ on a fresh-weight basis, which is probably enough to supplement iodine through dietary intake. In the current soil pot experiment, with iodine application at $1 \mathrm{mg} \mathrm{I} / \mathrm{kg}$ soil, iodine concentrations in spinach leaves were close to $3 \mathrm{mg} / \mathrm{kg}$. At the application of iodine at $5 \mathrm{mg}$ $\mathrm{I} / \mathrm{kg}$ soil, the accumulation of iodine in edible parts of spinach, pakchoi, and water spinach might lead to excessive intake and wastage of iodine. Based on the results from this experiment, it is recommended that the addition of $1 \mathrm{mg} \mathrm{I} / \mathrm{kg}$ to the soil might be appropriate to biofortify vegetable crops with iodine. However, this application rate will vary from soil to soil because the distribution coefficients for iodine between soil particle and the solution vary greatly between different soils (11).

One of the issues of soil application of iodine is the residual effect for subsequent planting. Data from this study showed that in the second planting, soil application of iodine could still significantly increase iodine accumulation in spinach as compared to the control (Treatment 1). However, the accumulation of iodine was much lower in the second planting than the first one. This reduction might be ascribed to a number of factors. One possibility is that iodine might be volatilized from the soil, although the volatilization rate of iodine in soils is unknown so far. In the current study, it was found that the reduction in total soil iodine as a result of plant uptake and loss to the air were generally less than $10 \%$; therefore in our case, iodine volatilization in a short-term experiment is not a problem. The second possible reason could be the reduction in the bioavailability of iodine in soil with aging. The third possibility is that the slight changes in growth condition in the greenhouse (e.g., daytime length and temperature) might cause the changes in iodine accumulation by spinach plants of the two experiments. Because biofortification of iodine through fertilization is relatively new, there is an urgent need to examine the fate of iodine (at the level of $\mathrm{mg} / \mathrm{kg}$ ) in soil-plant systems thoroughly for various soil types under different environmental conditions. Proper information on the fate of iodine in various soil-plant systems will not only improve the efficiency of iodine fertilization but also provide a better understanding of the regional variation in dietary iodine intake. Ideally, iodine supplementation through other programs should be guided by the information on the regional variations in dietary iodine intake. This information is particularly important if other programs of iodine supplementation, such as iodized salt, are to be maintained economically and safely on a site-specific basis.

Our data did suggest that iodine application can be carried over to the next cropping. However, the iodine concentration in the subsequent plantation might not be sustained if no further iodine application is made; this is quite usual for other normal fertilizers, such as phosphate and nitrogen. Although the loss and reduction in bioavailability of iodine in soils are inevitable, the development of controlled-release iodine-containing fertilizers might be a way to further improve the efficiency of iodine fertilization. 


\section{ACKNOWLEDGMENTS}

This project was supported by the Chinese Academy of Sciences (KZCX1-SW-19 and Hundred Talent Program).

\section{REFERENCES}

1 X. L. Hou, C. F. Chai, Q. F. Qian, et al., The study of iodine in Chinese total diets, Sci. Total Environ. 193, 161-167 (1997).

2 Y. G. Zhu, Y. Z. Huang, Y. Hu, et al., Iodine uptake by spinach (Spinacia oleracea L.) plants grown in solution culture: effects of iodine species and solution concentrations, Environ. Int. 29, 33-37 (2003).

3. P. Jopke, M. Bahadir, J. Fleckenstein, et al., Iodine determination in plant materials, Commun. Soil Sci. Plant Anal. 27, 741-751 (1996).

4 X. Y. Cao, X. M.Jiang, A. Kareem, et al., Iodination of irrigation waters as a method of supplying iodine to a severely iodine-deficient population in Xinjiang, China. Lancet 344, 107-109 (1994).

5. X. M. Jiang, X. Y. Cao, J. Y. Jiang, et al., Four-year experience in iodination of irrigation water in Hotien, Xinjiang province of China, Arch. Environ. Health 152, 399-408 (1997).

6. R. A. Herrett, H. H. Hatfield, Jr., D. G. Crosby, et al., Leaf abscission induced by the iodine ion, Plant Physiol. 37, 358-363 (1962).

7 C. L. Mackowiak and P. R. Grossl, Iodate and iodide effects on iodine uptake and partitioning in rice (Oryza sativa L.) grown in solution culture, Plant Soil 212, 135-143 (1999).

8. T. Shinonaga, J. Casta, K. Muck, et al., Determination of iodine in cereal grains and standard reference materials by neutron activation analysis, Int. J. Environ. Anal. Chem. 78, 175-184 (2000).

9 R. K. Lu, The Analysis Method of Soil Agricultural Chemistry, China Agricultural Science and Technology Publishing, Beijing (2000) (in Chinese).

10. G. W. Borst and F. H. Pauwels, Iodine as a micronutrient for plants, Plant Soil 14, 665-671 (1961).

11 J. L. Dai, M. Zhang, and Y. G.. Zhu, Adsorption and desorption of iodine by various Chinese soils: I. Iodate, Environ. Int., 30, 525-530 (2004).

12. Z. T. Gong, The system classify of Chinese soil, Science Publishing, Beijing (1999) (in Chinese).

13. X. L. Hou, C. F. Chai, Q. F. Qian, et al., Determination of Br and I in biological and environmental materials with ENAA, Fresenius J. Anal. Chem. 357, 1106 (1997). 